\title{
LINGUAGEM EM HUMANOS E CHIMPANZÉS Um problema de semântica
}

\author{
Augusta Gaspar e Teresa Avelar
}

\begin{abstract}
Resumo Neste artigo revêem-se os principais trabalhos dedicados à investigação da chamada "linguagem em chimpanzés" ou "capacidades cognitivas dos chimpanzés", tentando analisar e filtrar o que de concreto tais estudos demonstraram, os pressupostos e motivações que lhes estiveram subjacentes, bem como os seus problemas metodológicos. Reviu-se também um considerável número de conceitos, dado que o uso da palavra "linguagem" em sentido lato tem gerado grande confusão relativamente ao significado real e alcance da descoberta de capacidades cognitivas em Pongídeos, que, sendo condições fundamentais para a emergência de linguagem, ficam muito distantes da complexidade que define a linguagem humana.
\end{abstract}



\section{Nota prévia}

Este artigo refere diversos trabalhos efectuados em laboratório, o que equivale a dizer, em cativeiro. Tais estudos realizaram-se de forma tão invasiva quanto possível, ainda que saibamos que a maioria dos seus autores se preocuparam com o bem-estar dos seus objectos de estudo. Há uma posição que ambas as autoras do presente artigo partilham e que gostariam de, à partida, deixar claramente demarcada. Revêem-se e criticam-se as conclusões e implicações destes estudos. As nossas opiniões mais ou menos próximas de uns ou outros investigadores não reflectem a nossa apreciação relativamente à gestão dos seus laboratórios, à relevância dos seus projectos ou à criação de tais instituições para fins científicos. Convém esclarecer, por um lado, que existe actualmente (e esta situação dura há vários anos) um excedente de chimpanzés nascidos em cativeiro nos Estados Unidos (sobretudo em laboratórios da força aérea e em laboratórios de investigação médica), que atinge as centenas e que vai sendo mais ou menos assimilado por zoos, centros de acolhimento, outros laboratórios, universidades, centros de investigação. Quando estas instituições já existem e os chimpanzés em cativeiro também, o exercício de investigação acerca do desempenho em tarefas cognitivas tradicionalmente humanas parece justificável, desde que em condições eticamente aceitáveis, uma vez que na possibilidade mais drasticamente minimalista, mantém investigadores e Augusta Gaspar, dept. de Psicologia, Universidade Lusófona de Humanidades e Tecnologias, Campo Grande 376, Lisboa.
Teresa Avelar, dept. de Biologia, Universidade Lusófona de Humanidades e Tecnologias, Campo Grande 376, Lisboa e Unidade de Investigação em Eco-Etologia, Instituto Superior de Psicologia Aplicada, Lisboa. 
chimpanzés ocupados e assegura a sobrevivência a ambos. Ogrande desafio reside obviamente na criação de condiçōes progressivamente mais próximas das de que um chimpanzé disporia na natureza, quer do ponto de vista social quer do ocupacional. Os resultados da investigação laboratorial estão irremediavelmente condicionados e enviesados pela relevância das provas aplicadas a estes Pongideos. Graças ao testemunho dos investigadores no terreno, sabemos que os chimpanzés têm um desempenho bem mais brilhante em actividades que servem propósitos relevantes para a sua sobrevivência nas florestas da África Equatorial!

\section{Linguagem e linguagem humana}

Para além da compreensão gramatical das frases - i.e. respeitar as regras da sintaxe - e mostrar compreensão semântica - que mais restava para se acreditar que Was. hoe (Gardners) e Sarah (Premack) exibiam caracteristicas da linguagem humana capacidades linguísticas algures num contínuo onde se encontrava a linguagem humana?

Todo o debate foi obscurecido pelo facto de nunca se ter produzido uma definiçăo clara de "linguagem". As definiçốes foram mudando constantemente à medida que se tentava freneticamente demarcar diferenças, pois até entăo ninguém tinha tido realmente necessidade de produzir uma definiçâo da linguagem humana.

M. S. Dawkins (1993)

Marian Dawkins toca na ferida. De que falamos quando falamos de linguagem? Em primeiro lugar, falamos de linguagem humana, ou de um sistema de comunicaçăo mais global, passivel de ser partilhado, na sua integridade ou parcialmente, por várias espécies?

No que se refere à definição de linguagem humana, os psicolinguistas partem do pressuposto de que a primeira apresenta dois grandes níveis estruturais - a palavra e a frase, onde a relação entre a primeira e o que ela representa é arbitrária. Produzir frases implica um conhecimento da gramática, o que, por seu turno, permite gerar um número virtualmente infinito de frases.

Até ao surgimento dos primeiros resultados dos trabalhos de ensino de linguagem gestual, por Beatrix e Alan Gardner (1969) ou artificial, por David Premack (1971), a competência gramatical era inquestionavelmente assumida como uma característica que demarcava a linguagem humana dos restantes sistemas de comunicação animal. O esfusiante entusiasmo que despoletaram os relatos de chimpanzés a comunicarem com humanos através de combinações ou sequências de símbolos arbitrários fez estremecer as nunca antes questionadas presunçōes da psicolinguística e das ciências humanas. Uma análise mais detalhada destes primeiros resultados, bem como os projectos de investigação que se lhes seguiram, viriam a mostrar a verdadeira complexidade da questão $\mathrm{e}$ 
levaram ao esmorecimento de muito do investimento inicial neste tipo de estudos...

No interior da própria psicolinguística já existiam também duas vertentes opostas: behavioristas, por um lado, reivindicando que a linguagem era um comportamento como qualquer outro, podendo ser adquirida mediante a estimulação adequada; cognitivistas, por outro, inspirados sobretudo na escola de Chomsky, sustentavam que a linguagem resulta de uma especificidade biológica humana, pelo que não há aprendizagem que possa conduzir à sua produção.

\section{Condições necessárias e condições suficientes para que ocorra linguagem}

A questão do que é essencial à linguagem, i.e. a um modo de comunicação para que seja entendido como linguagem, sensus linguagem humana, é basicamente uma falsa questão, na medida em que tudo depende da perspectiva em que esta é encarada - tudo ou nada - como uma capacidade absoluta, ou como uma característica decomponível em capacidades que para ela concorrem; e, no último caso, que aspectos são enfatizados, sendo uns considerados mais importantes do que outros para definir linguagem. Ora, isto é tudo muito arbitrário, até porque os diferentes investigadores das capacidades linguísticas em Pongídeos foram destacando como fundamentais aspectos também distintos e, para um espectador exterior, é bastante evidente que são sublinhados os aspectos da linguagem que os seus objectos de estudo melhor mostraram dominar (e.g. Premack \& Premack, 1983; Savage-Rumbaugh, 1986):

Enquanto o linguista, por um lado, e o semiótico, por outro, reclamam prioridade para a sintaxe e para a intenção, como características básicas da linguagem, nós enfatizamos o papel crucial da capacidade de representação. Vemos a capacidade de representação como a capacidade para julgar a relação entre os acontecimentos reais e as suas representações. Se a linguagem for entendida como uma família de sistemas de representação, libertamo-la das limitações etnocêntricas e passamos a incluir os Pongídeos dentro dessa família. (Premack \& Premack, 1983).

De acordo com Savage e Rumbaugh (1977), o surgimento de símbolos arbitrários organizados por um sistema gramatical complexo ter-se-á dado a partir das expressões faciais, das posturas, das vocalizações, à medida que os actos de comunicação foram incluindo as representações separadas temporal e espacialmente dos eventos a que se reportavam. A comunicação analógica confunde-se ou justapõe-se mesmo ao evento, como sucede, por exemplo, com as expressões faciais espontâneas. Assim, para Sue Savage (actualmente Savage-Rumbaugh) e Duane Rumbaugh, a capacidade de separar os acontecimentos das suas representações é o elemento fundamental da linguagem - numa progressão que começaria nos sinais fisiológicos e progrediria até 
aos sinais arbitrários, passando pelos actos incipientes e pelos gestos icónicos (como estender a mão com a palma aberta para cima, que é característico dos chimpanzés).

Burlig (1993) contesta qualquer evolução da linguagem a partir de um sistema de comunicação primático anterior baseado quer em vocalizaçōes, quer em gestos ou expressōes faciais, sustentando que, a procurar alguma antiga estrutura noutros primatas que esteja relacionada com a linguagem, esta terá de ser ao nível de semelhanças em capacidades cognitivas relevantes e não no sistema de comunicação. A continuidade a partir das características da comunicação (particularmente em Pan e em proto-hominídeos semelhantes), por um lado, e a emergência de uma nova característica, presumivelmente com estruturas novas no córtex cerebral, por outro, sempre foram e continuam sem cessar a ser os dois grandes pólos do debate sobre a origem da linguagem humana (ver Jablonsky \& Aiello, 1998, para adiçōes recentes a este debate, em particular os artigos de P. Marler, L. Aiello e R. Martin). Mais recentemente, no pólo conceptual da "estrutura especial", uma equipa de investigadores do Medical College of Georgia liderada pelo Dr. Manuel Casanova (2001, com. pessoal) descobriu grupos de neurónios e respectivas conexōes no plano temporal do córtex humano, com assimetrias assinaláveis entre os hemisférios, sendo esta estrutura distinta em chimpanzés e outros primatas não humanos, cujos cérebros também năo apresentavam tal assimetria nestes grupos de neurónios.

A gradação proposta pelos Rumbaugh parece equivaler ao que seriam etapas da formação da linguagem. Mas não se entende bem o que estes investigadores querem dizer com elemento fundamental da linguagem - será condição sine qua non ou característica principal? A ser a primeira hipótese, é evidente que a separação entre a representação e o objecto representado é uma condição necessária à linguagem. Mas não é suficiente, isto ê, a linguagem humana não se situa no fim deste contínuo, porque a comunicação icónica já corresponde ao topo desta escala. Por outro lado, estes aspectos formam certamente uma progressão de complexidade, mas esta não tem forçosamente que corresponder a uma progressão ou um contínuo filogenético: podem depender de sistemas neurais diferentes, como aliás sucede entre os extremos da progressão onde, no ponto mais básico, são referidos sinais cuja emissão é involuntária e depende do sistema nervoso autónomo e, no último, sinais cuja emissão é voluntária, intencional e associada a uma complexa e extensa rede de representações em diferentes áreas do córtex. As várias operaçōes realizadas com palavras dependem de um número menor de sistemas neurais, geralmente situados no hemisfério esquerdo do córtex (Damásio \& Damásio, 1992).

Em comum, a proposta dos Premack e a dos Rumbaugh têm o facto de reduzirem a linguagem a um denominador comum a diversas formas de comunicaçăo, que nivela a linguagem muito abaixo da complexidade e possibilidades da comunicação verbal humana. Assim, numa tentativa de reduzir a entropia e os equívocos semânticos entre os vários autores e as várias posiçōes e correntes de pensamento, propomos referir linguagem como sinónimo de linguagem humana. Por outras palavras, "ter" linguagem significa "ter" linguagem humana. Como 
Quadro 1 Organização dos componentes da linguagem

Nível 1

Condições essenciais (necessárias mas não suficientes) para que ocorra linguagem

1) armazenamento extraordinário de informação - memória

2) capacidade de representação simbólica

3) capacidade de operar uma rede densa de representações simbólicas (arquivar, associar e evocar)

Nível 2

Condições cruciais para que ocorra linguagem:

a) surgimento da necessidade de veicular grandes quantidades de informação em pouco tempo b) surgimento de uma condição facilitadora da comunicação eficaz de uma grande quantidade de informação, compactada em símbolos ou signos articulados sequencialmente (a deslocação da glote e a consequente possibilidade de articular um número infindável de diferentes sons ou fonemas que se podem combinar para formar por seu turno palavras ou símbolos).

Nível 3

Condições que favorecem a complexificação da linguagem (densificação das regras e do vocabulário)

x) desenvolvimento das capacidades de memorização (armazenamento de representações), associação (transmodal) de representações e evocação.

y) motivação para comunicar quantidades massivas de informação, muito para lá do nível de utilidade imediata, como a que existe quando se comenta uma paisagem ou as próprias reflexões sobre um assunto.

b) (nível 2) pode influenciar $x$ (nível 3)

Nota: A separação dos componentes por niveis - condições essenciais, básicas e sem as quais a linguagem não poderia ocorrer, condições cruciais e condições que favorecem a sua complexificação ajudam-nos a compreender quão limitadas são as conclusões que se podem retirar dos estudos de "Linguagem em chimpanzés". Cumprir os requisitos do nível I não significa ter "linguagem" (sensus linguagem humana, com a complexidade com que esta se manifesta).

existem, com efeito, várias características assinaláveis para a linguagem (por exemplo, as definidas por Hockett, 1960, ou por Thorpe, 1972), referir-nos-emos a alguns aspectos da mesma, por rudimentares que se afigurem, observados com sucesso em chimpanzés em laboratório, como isso mesmo - produtos possíveis em condições artificiais e que representam apenas o sucesso em encontrar aspectos fragmentários da linguagem humana. A importância desses resultados depende da importância relativa desses componentes na linguagem, bem como da antiguidade filogenética dos mesmos. Não é de estranhar, todavia, que outras espécies tenham algumas capacidades necessárias mas não suficientes para que a linguagem exista, e que a experimentação as evidencie, como não é de estranhar que se tenham encontrado também essas capacidades nas espécies vivas mais próximas; nada nos diz, porém, que tivesse a investigação sido protagonizada por outros mamíferos, 
elas não estariam também lá. Infelizmente, a questão tem sido pouquíssimo abordada em outros grupos que não a Ordem dos Primatas.

Seria bem mais simples tratar toda a questão numa concepção simples, em que não se confundissem as condiçōes essenciais (i.e. necessárias mas não suficientes) à ocorrência da linguagem (e por isso largamente partilhadas entre espécies), com as condições cruciais para a emergência da linguagem (para não falar que as condiçōes reais que a fizeram surgir existem apenas em planos de reconstrução especulativa); perante uma linguagem já existente, ou seja, já à saída da caixa-negra da origem da linguagem, podemos com alguma plausibilidade referir-nos às condiçōes que favoreceram a complexificação da linguagem, no sentido de produzir códigos elaborados como os hoje usados por todos os humanos (ver quadro 1).

\section{Mas afinal, como se define a linguagem humana?}

Não existe uma definição compacta e universalmente aceite do que é a linguagem humana. Segundo Pinker (1995), no estudo formal da gramática, a linguagem é um conjunto (possivelmente infinito) de frases, em que cada frase é uma sequência de símbolos (palavras). Frases novas podem ser produzidas e compreendidas por qualquer ser humano normal. A linguagem usa um código, i.e. um conjunto de regras (a gramática generativa) que determina a forma e o significado das palavras e frases. Inclui a sintaxe (as regras sobre o arranjo das palavras em frases) e a semântica (as regras que especificam o significado das palavras e frases). A ambas está subjacente o léxico (o "dicionário" mental de significados dos símbolos) e a fonologia, i.e. as regras que organizam a produção dos sons.

É de sublinhar que, para que a linguagem seja possível, é necessário mas não suficiente que se possa formar representações mentais complexas do mundo e manipulá-las mentalmente.

A gramática é um "sistema combinatório discreto" (discrete combinatorial system), em que um número finito de elementos discretos (palavras) é escolhido, sendo tais elementos combinados e permutados de modo a criar estruturas maiores (frases) com propriedades distintas das dos seus elementos (ver Pinker, $1994 a, b)$. Esta característica da gramática permite-lhe produzir um número infinito de frases diferentes e o código é autónomo, na medida em que a especificação das regras é independente do significado particular. Assim, pode haver frases compreensíveis embora não gramaticalmente correctas (esta frase nāo verbo) e frases gramaticalmente correctas mas sem significado (como aquela, famosa, que Chomsky propôs: colorless green ideas sleep furiously), o que indica uma certa independếncia entre a sintaxe e a semântica.

A estrutura gramatical é hierárquica (embora a produção sonora ou gestual de frases seja linear). Componentes essenciais da estrutura são itens gramaticais, 
que não se referem a elementos concretos do mundo exterior, e que constituem cerca de metade das palavras utilizadas na linguagem humana, por exemplo preposições (DE, PARA, EM, ANTES, etc.), conjunções (MAS, ONDE, NEM, PORQUE, etc.), prefixos e sufixos (AR em andar), plurais, tempos verbais, indicações de caso (DELE, SEU, etc.).

No que respeita às capacidades subjacentes à emergência da linguagem antagonizam-se habitualmente duas grandes posições:

- Uma, sustentando que a linguagem reflecte capacidades cognitivas gerais, sendo uma consequência oportunista das mesmas, i. e. não tendo sido seleccionada em si, mas resultando da acção da selecção natural sobre outras capacidades (i. e. sendo uma exaptação, no sentido de Gould e Vrba, 1982). É a posição de Piatelli-Palmarini (1989) e de Savage-Rumbaugh \& Rumbaugh (1993). Note-se que Piatelli-Palmarini mostra dominar mal a moderna teoria evolutiva quando se refere à substituição da selecção natural por uma teoria evolutiva, "melhor" baseada na exaptação... A tese de que a linguagem é uma mera consequência de aptidões cognitivas gerais pode servir para nos congratularmos com o desenvolvimento da nossa inteligência: somos tão inteligentes que falamos; outras espécies são um pouco menos inteligentes e quase falam, basta uma pequena ajuda nossa...

- Outra corrente, cujo argumento básico, defendido por Chomsky e os seus seguidores, e.g. Pinker (1994a, b, 1995), é a que defende que a capacidade humana de aprender e utilizar a linguagem é inata, sendo esta capacidade (e a linguagem em si) uma característica específica humana, do mesmo modo que a capacidade em memorizar a localização de milhares de esconderijos de sementes é específica de algumas aves (por exemplo o corvídeo Nucifraga columbiana e os chapins Parus palustris e P. atricapillus: Shettleworth, 1983; Sherry \& Duff, 1996). Decorre desta teoria que, embora elevadas capacidades cognitivas possam ser necessárias para que ocorra linguagem, não são suficientes, dado que a última é uma especialização particular. Decorre ainda desta visão que outros animais com elevadas capacidades cognitivas podem perfeitamente não possuir capacidades linguísticas. Os dados apoiando esta teoria, e difícilmente explicados pela teoria antagónica, incluem:

1) A existência de especializações anatómicas ao nível da laringe, permitindo a articulação de sons. Este factor é o menos importante, visto que as linguagens gestuais dos surdos-mudos têm todas as características importantes das linguagens faladas, mas existe e reflecte pressões selectivas que apenas ocorreram na linhagem humana.

2) O modo como as crianças aprendem, o que fazem não simplesmente copiando as frases que ouvem, mas adquirindo um domínio de regras gramaticais complexas apenas por ouvirem os adultos falar, o que seria impossível se não possuíssem as regras a priori. Note-se que em algumas culturas (embora não a cultura ocidental actual), os adultos praticamente não falam com crianças com idades pré-linguísticas (argumentando que não vale a pena) e estas, no 
entanto, aprendem a falar normalmente, passando por estados semelhantes nas várias culturas investigadas (Pinker, 1995). Assim, crianças de 3-5 anos conseguem imediatamente formar a pergunta correcta a partir da frase: The boy who is sad is watching Mickey Mouse, o que dá: Is the boy who is sad watching Mickey Mouse? Ora, como sabem qual o is que deve ser colocado no início da frase? Além disso, as crianças passam por um período em que fazem erros sistemáticos devido a generalizarem uma regra (em vez de simplesmente imitarem os adultos). Por exemplo, dizem: I goned to school, he holded the babies, etc., porque generalizam a regra inglesa dos tempos verbais passados $(+e d)$, aplicando-a exclusivamente a verbos (como sabem o que é um verbo?) e mesmo em diálogos com um adulto que usa a forma correcta (o que indica de modo particularmente óbvio que não estão a imitar). Ou dizem: tooths, mouses, etc., porque generalizam a regra do plural $(+s)$, aplicando-a apenas a substantivos (como sabem o que é um substantivo?). Finalmente, as crianças aprendem a utilizar itens gramaticais sem ninguém lhes explicar a função destes (experimente-se ensinar o significado de MAS, SE, PARA, etc.)

3) A capacidade das crianças, dentro do período crítico, para desenvolverem uma linguagem mais organizada e complexa do que aquela a que estão expostas, indicando que estão a utilizar regras inatas, que não existem no seu ambiente: é o caso das crianças que falam crioulo apesar dos pais falarem pidgin. O pidgin é uma linguagem simplificada, usada entre adultos com línguas diferentes e que têm que comunicar mas que, por razões várias, não podem aprender as línguas uns dos outros. No pidgin não há ordem consistente das palavras, prefixos ou sufixos, plurais, tempos verbais, indicadores temporais e de caso, etc., isto é, em geral não há itens gramaticais a não ser os que têm significado semântico (NÃ̃, QUEM, MAIS) e não há estruturas mais complexas do que uma única cláusula. No entanto, nas línguas crioulas, já há ordem consistente das palavras, verbos auxiliares para indicar tempos verbais, itens gramaticais como preposições, pronomes, prefixos, sufixos, e estruturas mais complexas do que cláusulas únicas. Isto significa que as crianças em contacto apenas com o pidgin desenvolvem todas estas complexidades sem estarem expostas a elas. Além disso, a estrutura de todos os crioulos é semelhante, qualquer que seja o vocabulário básico dos pidgin.

4) A existência de um período crítico (idealmente antes dos seis anos, quando muito até à puberdade) necessário para que a aquisição da linguagem seja normal. Fora desse período, os seres humanos só conseguem dominar o equivalente a um pidgin. Se a linguagem resultasse apenas de capacidades cognitivas gerais, não faria sentido o período crítico ser muito mais rígido do que para a aprendizagem de outras estruturas complexas, como a aritmética.

5) A existência de zonas do cérebro especializadas para a produção e compreensão da linguagem, e que incluem, por exemplo, sistemas conceptuais representando o significado (semântica), sistemas representando os sons (fonologia) e um sistema lexical independente da modalidade, e que medeia entre os dois sistemas referidos anteriormente (Damásio et al., 1996). O hemisfério esquerdo é em geral dominante no que diz respeito à produção 
linguística, quer esta seja verbal ou gestual, como foi demonstrado recentemente em relação ao ASL (American Sign Language), indicando que a produção de gestos linguísticos está dissociada da produção de gestos não linguísticos (Hicok et al., 1996). Existem, também, deficiências neurológicas específicas para a linguagem (i. e. que não afectam outras capacidades cognitivas (Damásio \& Damásio, 1992; Gordon, 1990).

(6) A possível existência, quer de constrangimentos, quer de características universais, em todas as línguas conhecidas, e que não podem ser explicados através de consideraçōes funcionais, sugerindo assim uma origem nos próprios constrangimentos mentais humanos (Pinker, 1995).

(7) Aexistência de pessoas cognitivamente normais mas com deficiências especificamente linguísticas, ou porque têm lesões neurológicas, ou porque não aprenderam a linguagem durante o período crítico. Por exemplo, a existência de Specific Language Impairment (SLI), ou seja deficiências linguísticas (incapacidade em produzir plurais, utilizar sufixos, pronomes, tempos verbais passados, etc.) que não podem ser atribuídas a problemas de audição, problemas musculares ou deficiências cognitivas gerais, e que são transmitidas geneticamente. Por exemplo, um membro afectado de uma familia com SLI não consegue passar o Wug Test; no entanto essa mesma pessoa teve excelentes notas em matemática na escola e é programador de computadores (ver Gopnik \& Crago, 1991). O Wug Test é utilizado com crianças para ver como é que elas formam o plural: mostram-se-lhes imagens de um gato e dois gatos ou imagens de um ser imaginário, um wug, e depois dois... e elas imediatamente conseguem dizer dois Wug. Apesar de desconhecermos a representatividade estatística destes fenómenos, ou a sua eventual raridade, tais ocorrências não podem ser ignoradas ao formular uma teoria sobre a linguagem, como o parecem fazer Savage-Rumbaugh e Rumbaugh (1993), com a afirmação: "não existe nenhum componente neurologico exclusivo dos processos linguísticos $e$ independente das funçōes cognitivas gerais" (ênfase no original).

A separação entre capacidades linguísticas e capacidades cognitivas gerais é também apoiada pela existência de pessoas com deficiências mentais profundas (do ponto de vista cognitivo geral), mas com linguagem fluente, gramaticalmente correcta. No caso da síndroma de Williams, em que o QI é inferior a 50 e as pessoas afectadas não conseguem levar uma vida normal, conseguem produzir e interpretar frases complexas com várias cláusulas (podem dizer, ao contar uma história: if the sun changes to a different colour, then the chocolate world won't melt), detectam erros gramaticais e têm uma preferência por palavras raras. Estes dados são, todavia, os menos consistentes porque a questão é se compreendem perfeitamente o que dizem, uma vez que parte da produção pode dever-se a imitação. O conceito de capacidades linguísticas fica aqui circunscrito à capacidade de se exprimir verbalmente (dentro de vários graus possíveis de compreensăo). Deacon (1992), referindo-se às afasias transcorticais (que podem estar relacionadas com lesõ̃es em várias regiōes do córtex - mas não nas áreas de Wernicke e Broca - com consequências que dependem de quais as zonas mais afectadas), reporta como as associadas frequentemente 
a lesões próximas da área de Wernicke se exprimem numa fraca compreensão das produções verbais, como as associadas a lesões na área motora reduzem o discurso espontâneo e originam uma estrutura frásica simplificada, mas em qualquer dos casos as pessoas repetem bem as frases que ouvem, memorizam-nas e nalguns casos exibem mesmo uma tendência para repetir ou completar frases que ouviram imediatamente antes, completando correctamente frases banais e memorizando bem as letras de canções, por exemplo. Não podemos deixar de ter presente o facto de existir todo um conjunto de diferentes estruturas neurais subjacentes respectivamente a níveis distintos de representação simbólica, e que se distribuem não só por ambos os hemisférios e por várias regiões sensoriais e motoras do córtex e não são apenas circunscritas às zonas de Wernicke e Broca (Damásio \& Damásio, 1992; Deacon, 1992), e que se observou também através das técnicas de mapeamento da circulação sanguínea cerebral e de tomografia de emissão de positrões, que a distribuição espacial das funções linguísticas varia de pessoa para pessoa, não é possível descartarmo-nos facilmente da possibilidade de muitas capacidades linguísticas estarem dependentes de outras funções cognitivas e de essa dependência apresentar consideráveis idiossincrasias. Não há dúvidas de que as lesões nas áreas de Broca e Wernicke comprometem a linguagem. O facto de existirem raríssimos exemplos de pessoas com deficiências cognitivas e com um discurso verbal correcto, poderá ter outras explicações, que não a de um divórcio entre capacidades cognitivas gerais (dito deste modo) e linguagem. Há também níveis de complexidade que não permitem esta dissociação; basta que a pessoa conserve algumas funções de representação e evocação dessas representações — se não puder fazer representações complexas do mundo também não as poderá comunicar.

Logo, também não é possível, em absoluto, divorciar capacidades linguísticas de outras capacidades cognitivas, ainda que seguramente não exista uma relação de dependência de um factor geral de inteligência.

\section{"Linguagem" em chimpanzés?}

A realização de projectos de investigação que visavam grosso modo estudar a existência de uma possibilidade de comunicar com "linguagem" em chimpanzés (e também gorilas e orangotangos, sobre os quais não nos vamos debruçar, dado que os trabalhos laboratoriais sobre questões linguísticas com estas espécies foram muito mais raros e sujeitos a menor controlo) baseou-se em três argumentos:

1) A vontade de quebrar o "isolamento" (assimilado a uma eventual ideia de "superioridade" que se quer combater) da espécie humana e de demonstrar que a linguagem não é na realidade o "último bastião" da natureza humana (ver Linden, 1974). A afirmação com que Savage-Rumbaugh \& Rumbaugh (1993, p. 106) concluem o seu artigo sobre as capacidades linguísticas de um 
bonobo ("By viewing language as the inevitable outcome of the social interactions of intelligent creatures, humankind may lose some sense of uniqueness but gain in return a deeper understanding of itself") é particularmente elucidativa sobre os seus pressupostos. Pergunta-se aliás: se a aquisição de linguagem é um resultado inevitável da interaç̧ăo entre seres sociais, porque é que os animais sociais inteligentes, a começar pelos bonobos, não adquirem linguagem, nem mesmo pidgin, na natureza, mas apenas quando estão em contacto prolongado com os seres humanos? O desejo de acabar com a posição "única" dos humanos está associado à ideia de que, ao explorar as capacidades dos chimpanzés, (os nossos parentes vivos mais próximos), automaticamente conheceremos melhor as nossas, que são apenas extensões daquelas que os chimpanzés já possuem.

2) Pressupostos behavioristas de que qualquer comportamento pode ser ensinado com o reforço, ou no ambiente, correcto, independentemente das disposiçōes inatas. Esse pressuposto existe não só no caso dos Gardner (ver Wallman, 1992), como no dos Rumbaugh: por exemplo, Savage-Rumbaugh (1993, p. 458) advoga o strong L (learning) position: "other complex brains should also be capable of some simple language given the proper experience".

3) A afirmação que a linguagem pode ser dissociada em vários componentes e que a pergunta: "os chimpanzés possuem ou não linguagem?" é demasiado simplista. Sendo óbvio que os chimpanzés não possuem todos os componentes da linguagem humana, é no entanto interessante explorar se possuem alguns.

Antes de prosseguirmos com o que se propõe ser uma análise crítica destes fundamentos e das conclusões produzidas pelos referidos trabalhos, vamos resumidamente descrever o seu historial, começando pelos estudos onde se procurou dar um código não vocal de comunicação aos chimpanzés (uma vez que os imensos esforços para pôr um chimpanzé a articular oralmente palavras se tinham mostrado anteriormente estéreis, dado que esta espécie não possuiu um aparelho fonatório adequado à produção de palavras).

Tudo começou com Washoe, uma fêmea de Pan troglodytes, criada a partir de um ano de idade numa casa humana $e$ treinada (por condicionamento operante) por Alan e Beatrix Gardner na utilização de ASL - American Sign Language (na realidade, uma versão pidgin, uma vez que nenhum dos treinadores se exprimia fluentemente em ASL, desconhecendo aparentemente a verdadeira complexidade desta linguagem gestual, como foi verificado pelo único investigador envolvido que era surdo e fluente em ASL: ver Wallman, 1992, p. 54). Washoe aprendeu mais de 200 gestos, representando palavras através de um método de moldagem das mãos na postura correcta, e aprendeu apenas alguns sinais por observação. Washoe combinava palavras, e como em $90 \%$ das suas produçōes com três palavras ela colocava o sujeito antes do verbo, foi considerado pelos Gardner que ela possuía algumas capacidades gramaticais (Linden, 1974). Olinguista Roger Brown desvaloriza este achado, assinalando que entre diferentes línguas existem também 
diferenças no uso da ordem das palavras e que em algumas esta é menos importante que em Inglês, sendo menos importante em ASL que em inglês escrito (in Linden, 1974).

Outro estudo que surgiu pouco depois foi o de Sarah, uma fêmea de Pan troglodytes, que foi treinada por David Premack (Universidade da Pensilvânia) a utilizar símbolos visuais arbitrários inscritos em fichas plásticas, que Sarah deveria sequenciar quando queria formular um pedido ou outro tipo de frase. O móbil de Premack - aceder ao mundo cognitivo do chimpanzé - fazendo recurso a um código linguístico, foi largamente frustrado, apesar de uns pequenos "sucessos". Piaget tinha afirmado que "ensinar linguagem a um animal, consiste sobretudo em organizar o conhecimento já possufdo pelo animal" (in Linden, 1974). Premack receava que Sarah não dominasse alguns conceitos que teriam de ter sido adquiridos antes do seu treino linguístico, como as relaçőes que caracterizam o condicional. Alguns símbolos usados por Sarah corresponderiam efectivamente a conceitos pré-existentes no chimpanzé e cuja existência se poderia confirmar perante a utilização adequada dos símbolos para "igual-diferente" ou "nome de".

Terrace veio acender o debate. Em 1974 dera início a um estudo das capacidades linguísticas de um macho infantil de Pan troglodytes - Nim Chimsky - que foi treinado em (pidgin) ASL por Terrace e seus colaboradores (ao todo $60 \mathrm{em}$ 4 anos 1), utilizando o método de ensino aplicado pelos Gardner. Volvidos cinco anos, sustentava que as palavras produzidas por Nim eram desprovidas de sintaxe, como seriam as de Sarah (o chimpanzé dos Premack), acusando os Gardner de falta de rigor e controlo das suas experiências. Os chimpanzés estariam apenas a tentar obter recompensas via os símbolos e poderiam nem sequer os compreender. Por essa altura, Sebeok compara as produçōes de Washoe à do "Clever Hans" - o cellebre cavalo que acertava as contagens graças à capacidade de detectar sinais subtis de aprovaçăo no rosto do seu dono -, sustentando que os chimpanzés com as alegadas capacidades linguísticas mais năo fazem do que imitar os seus treinadores, procurando agradar-lhes.

Entretanto já surgira, em 1970, um estudo, metodologicamente mais aperfeiçoado, formulado por Duane Rumbaugh - o Projecto Lana (Lana era o objecto de estudo: uma fêmea bebé de chimpanzé comum) -, onde se introduzia um sistema electrónico que treinava o chimpanzé e registava integralmente os dados (todas as suas "transaç̧ōes linguisticas", operando 24 horas por dia, sete dias por semana. Lana interagia com o computador através de um teclado, onde se representavam lexigramas representando palavras. Este novo código, a que foi dado o nome de yerkish, contém 42 classes conceptuais de lexigramas (Glasersfeld, 1977), das quais se assinalam apenas sete, como exemplo: estados (as cores, limpo, sujo, duro, macio, quente, frio), preposiç̋les direccionais (atrás, para dentro de, fora-de), marcadores de semelhança/diferença (igual a, diferente de), actividades perceptivas (sentir, ouvir, ver), demonstrativos (isto, o que), quantitativos (todos, muitos, nenhuns, um), Comparativos (menos, mais). A concepção deste projecto já permitia controlar o efeito de Clever Hans. O yerkish foi concebido apenas com voz activa e três tipos de frases - declarativas, interrogativas e imperativas. $\mathrm{O}$ 
símbolo? foi incluído neste código e a sua utilização foi convencionada para o princípio da frase interrogativa; a imperativa (ou pedido/solicitaçăo) é indicada pelo símbolo please e a declarativa (ou comentário) não é precedida por nada. Assim, temos por exemplo: como frase declarativa - Tim move into room; como frase. interrogativa - ? Tim move into room; e, como frase imperativa - Please Tim move into room. Aos quatro anos de idade, a proporção de sequências não gramaticais de quatro, cinco ou seis lexigramas produzidas por este chimpanzé era de 71/125.

Também Roger Fouts, co-responsável com Deborah Fouts por um laboratório de investigação da comunicação em chimpanzés na Washington Central University (onde reside actualmente Washoe com o seu filho Loulis e outros três chimpanzés com uma história de vida parecida) na década de 70, dava a conhecer o facto de ter registado com uma câmara de vídeo e sem que os chimpanzés dessem conta de estar a ser observados, a comunicação entre eles com a linguagem gestual que tinham aprendido. Washoe ensina Loulis, seu filho adoptivo, através do mesmo tipo de metodologia com que ela própria havia sido ensinada (moldagem das mãos nos gestos do ASL), a comunicar com alguns símbolos gestuais. Depois disso, repetidas vezes - é aliás um acontecimento frequente naquele laboratório (Fouts \& Fouts, 1989), surgem relatos de episódios de diálogo e monólogo em ASL por parte dos chimpanzés desta colónia. Loulis inclui, em cerca de $11 \%$ das interacçōes que ele próprio inicia com outros chimpanzés, os símbolos que aprendeu (Fouts \& Fouts, 1989) em dados colhidos por câmara com controlo remoto e portanto sem a presença de observadores humanos. De resto, as observações comportamentais contabilizadas neste laboratório são em grande parte efectuadas por observadores escondidos, sem que os chimpanzés tenham conhecimento de que estão a ser observados.

David Premack recua na sua conclusão de que Sarah produzia sequências gramaticais (1971; Premack \& Premack, 1983) e em 1980 (cit. por Terrace, 1986) Sue Savage-Rumbaugh, Duane Rumbaugh e Sarah Boysen concluíram que os dados existentes sobre combinações de símbolos por Pongídeos não justificavam a sua interpretação como frases. Premack \& Premack (1983) referem-se às sequências de símbolos elaboradas e utilizadas por Sarah como construções e não como frases, alegando que "a construção não possui uma organização interna e que, ao contrário da frase (onde as palavras se definem na relação que têm entre si e são independentes do mundo), as suas componentes não apresentam uma relação entre si, sendo a sua aparente organização fruto da relação dos elementos da construção com o mundo". O que Premack pretende dizer é que o conteúdo semântico das construções de Sarah é dependente do contexto.

Mais tarde, Premack e Premack (1983) acabam por propor a existência de três tipos de mente: as que estão especializadas na imagem - não têm código abstracto nem linguagem -, são incapazes de reconhecer representações da aç̧ão e não fazem atribuições sociais; outra, que os humanos partilhariam, possui imagística (imagery), um código abstracto e linguagem; os chimpanzés situar-se-iam num tipo de mente, que, para além da imagística, teria uma capacidade de representação 
abstracta. "O ensino de linguagem a este tipo de mente não confere ao aprendiz linguagem humana, mas parece melhorar a capacidade de resolução de problemas abstractos".

Em resposta às críticas de trabalhos anteriores, designadamente a de que os chimpanzés poderiam estar a imitar os experimentadores, Sue Savage-Rumbaugh inicia com dois machos de chimpanzé comum, Sherman e Austin, um projecto largamente inovador e que foi objecto de grande aprovação pelo céptico Terrace, começando por distinguir claramente a produção da linguagem da compreensão da linguagem. De acordo com esta investigadora o precursor verdadeiramente crucial da competência linguística é a compreensão de símbolos, e resolve começar por se concentrar no estudo da compreensão dos mesmos e não na produção. Verificou-se que o Sherman e o Austin faziam efectivamente muito mais do que imitar os treinadores - transmitiam um ao outro (encontrando-se em salas diferentes e sem contacto visual) informaçăo relevante (como a da localização de um alimento), dependendo exclusivamente do código aprendido (pois não tinham contacto visual ou auditivo) e via computador.

Terrace faz notar, como aliás Savage-Rumbaugh, que quando um chimpanzé aprende a usar um símbolo para obter algo num determinado contexto não sabemos se ele é capaz de o utilizar em outro contexto ou se ele entendeu que o tal símbolo também serve para designar ou identificar um objecto, sobretudo se o chimpanzé já assistiu a alguém utilizar esse mesmo símbolo para solicitar exactamente a mesma coisa. Com o paradigma experimental original introduzido no projecto de Shermane Austin, a compreensão do símbolo fica demonstrada. No referido paradigma eles solicitam objectos um ao outro a partir de salas separadas; a um deles é dado observar uma localização onde se encontra comida, sendo necessário um determinado objecto para aceder a esse alimento, enquanto o segundo chimpanzé tem acesso a uma caixa com objectos vários, inclusive o instrumento necessário ao primeiro chimpanzé, não tendo, porém, acesso físico ao alimento. Para que este último forneça a ferramenta necessária ao primeiro é preciso que aquele formule o pedido, utilizando o símbolo apropriado; quando o outro tho envia, ele resolve o problema de acesso ao alimento e partilha-o com o segundo chimpanzé.

SeShermane Austin tinham aprendido a comunicar em yerkish através de um treino metódico, já no projecto que se seguiu, Savage Rumbaugh optou por expor à linguagem oral (língua inglesa) e gestual humana normal dois bonobos (Pan paniscus) infantis - Kanzi e Mulika - comunicando também à sua frente com o yerkish em contextos quotidianos (com quadros portáteis contendo os lexigramas) e sem condicionamento operante, i.e. sem recompensa pela compreensão e utilização correcta dos símbolos (Greenfield \& Savage-Rumbaugh, 1990). Sabe-se actualmente que os bonobos em meio natural possuem um reportório de gestos que se considera superior ao dos chimpanzés comuns, embora não seja certo que Savage-Rumbaugh já tivesse tal informação disponível quando iniciou o projecto de estudo dos bonobos. Assistindo às sessões de treino da sua mãe Matata, Kanzi começou espontaneamente a utilizar lexigramas em contextos adequados. Esta 
aprendizagem natural ocorreu com os primeiros sete lexigramas do seu vocabulário, linguagem oral dos treinadores e à utilização de lexigramas. Ao cabo de quatro meses com este regime de treino, Kanzi tinha adquirido 20 símbolos, e em 17 meses, 50 símbolos, produzindo também combinações espontâneas dos mesmos. Aos dez anos, Kanzi dominava 200 símbolos. $90 \%$ das suas 2800 diferentes expressões através de lexigramas eram originais, ou seja não tinham sido ensinadas por nenhum dos treinadores. Adquirira também inúmeros gestos humanos. (Note-se, no entanto que, dado que Kanzi presenciara o longo treino de Matata, a sua exposição inicial à linguagem foi muito mais metódica e repetida do que a de uma criança, embora se admita que depois disso o não tenha sido). Quanto à compreensão das palavras produzidas oralmente, Kanzi mostrou-se capaz de entender, em condições altamente controladas, instruções várias. De acordo com Greenfield \& Savage-Rumbaugh (1990), este bonobo adquiriu também regras gramaticais simples (como a ordem, por exemplo, a acção a preceder o objecto) e inventou também as suas próprias regras - por exemplo, nas frases em que se combinam várias acções, onde tipicamente ele coloca primeiro os lexigramas que representam um convite ao jogo e em segundo lugar os que apresentam o conteúdo do jogo.

Terrace criticou também algumas das conclusões de Savage-Rumbaugh no estudo de Kanzi. Mas são críticas diferentes das que fazia aos estudos com a Washoe, com Nim e Sarah. Pode dizer-se que Terrace subiu a parada, ao argumentar que Kanzi não apresenta uma linguagem rudimentar, na medida em que usa os símbolos para obter coisas, para solicitar algo e não para partilhar informação acerca da sua percepção do mundo, como os humanos fazem ("eu vi tal e tal"). Savage-Rumbaugh replica que se trata de uma questão de gradação, referindo que as crianças também usam predominantemente os símbolos para solicitar coisas. Além disso, como resposta, Savage-Rumbaugh também apresenta o uso de referência.

\section{Reflexões por fazer}

Cumpridos, entretanto, os requisitos de controlo e rigor para que a comunidade científica aceitasse, em primeiro lugar, que os chimpanzés tinham realmente aprendido o conteúdo dos símbolos que manipulavam e eram capazes de responder a diversas instruçōes e questões colocadas através da utilização desses símbolos, não estavam a imitar o experimentador ou a reagir a indícios por ele emitidos, $\mathrm{e}$ em segundo lugar, que tomavam a iniciativa de os utilizar para efectuar pedidos ou, muito mais raramente, comentar algum acontecimento, qual era a crítica que permanecia relativamente a estes trabalhos com chimpanzés?

A questão subiu, portanto, alguns níveis desde os primeiros trabalhos acima referidos, ou não seria ainda objecto de controvérsia. Será que podemos considerar 
que uma interacção entre um homem e um chimpanzé ou entre dois chimpanzés, mediada por um código linguístico artificial, uma forma de comunicação linguística? E, qual é a relevância, afinal, de competências simbólicas ou linguísticas observadas em condições tão artificiais como as acima descritas, para a história natural do chimpanzé? Ou para a reconstrução filogenética da origem da linguagem?

Tem-se especulado que alguns comportamentos dos chimpanzés ferais reflectem capacidades cognitivas reveladas em laboratório. Algumas actividades poderiam ser consideradas precursoras de estruturas gramaticais simples (Ristau \& Robbins, 1982) - a utilização de uma estrutura gramatical implica, no mínimo,o conhecimento de certos tipos de relaçōes, estabelecendo-se um paralelo entre estruturas sujeito-verbo-objecto e as categorias de actor, actuar e as coisas sobre as quais se actua. $\mathrm{O}$ facto de os chimpanzés fabricarem e utilizarem utensflios é interpretado como evidência de que eles conhecem essas categorias de relações. A compreensão da proposição "em/dentro de" (in) também estaria presente na utensilagem, por exemplo quando os chimpanzés introduzem pequenos caules transformados nos túneis das termiteiras para colher térmites. Aliás, Calvin (1993) também sugere como cenário plausível que fala, técnica (no sentido de utensilagem) e pensamento podem ter co-evoluído, e que as mudanças de função de uma estrutura podem ser profundas e dar origem a uma nova função. O cérebro pode facilmente combinar esquemas sensoriais e programas motores de novas maneiras, associar elementos sob a forma de uma sequência em algumas das seguintes "subfunções": fabrico e uso de utensílios, que implica fazer uma nova sequência de movimentos; produzir uma "expressão" nova a partir, por exemplo, das 36 diferentes vocalizaçốes dos chimpanzés (com 36 diferentes significados), 0 que implica pôr duas em sequência; criar um novo plano de acção, o que equivale a elaborar mentalmente um cenário sequencial, que é justamente uma especialidade do hemisfério esquerdo (Kimura, 1979, cit. por Gibson, 1993). A ideia de que a capacidade de sequenciar etapas de um plano de acção bem como o planeamento em função de um alvo são capacidades que podem ter evoluído a par da linguagem é partilhada por Davidson e Noble (1993; que se destacam entre outros autores em Gibson \& Ingold, 1993) e está presente em Vieira (1994; 1995). A capacidade de conceber uma sequência de eventos e as subjacentes relações causa-consequência, parecem evidenciar-se nas actividades de caça cooperativa (Ristau \& Robbins, 1982), onde os indivíduos se reúnem, repartem tarefas e se coordenam entre si de tal modo que, dependendo da acção de um, toda a actividade de outro é imediatamente alterada, numa coordenação improvisada passo a passo, mas também com um objectivo antecipado (por exemplo, parte da perseguição, até à emboscada, é silenciosa). Por exemplo, é suposto que os capturadores que fecham o cerco saibam o que fazer se o batedor fizer isto ou aquilo.

Retornando à polémica actual da origem da linguagem - i.e. se esta evoluiu a partir de outras competências cognitivas ou se, pelo contrário, depende de uma estrutura completamente nova no homem e que não é partillhada por nenhum dos seus parentes vivos, tendo existido possivelmente no já extinto homem de 
Neanderthal (Deacon, 1989; in Lewin, 1993) —, podemos assinalar, em primeiro lugar, que as grandes justificações em que se funda a legitimação destes projectos de estudo de capacidades linguísticas em chimpanzés (baseados na convicção da continuidade filogenética e da existência de capacidades cognitivas partilhadas por humanos e Pongídeos na origem da Linguagem) carecem de sustentação suficiente.

Os pressupostos behavioristas são tão "arcaicos" que quase não vale a pena tornar a criticá-los. Basta referir mais uma vez que diferentes espécies possuem capacidades de aprendizagem diferentes, e especializadas. Não é pois de modo nenhum garantido que a linguagem, na sua verdadeira complexidade, possa ser aprendida por uma espécie que não possua disposições inatas para a aprender.

Quanto à tentativa de demonstrar que o homem não está isolado no mundo animal, mas é produto, como os outros, de uma história filogenética, há que esclarecer sem demoras que isso não significa que a evolução não caminhe numa direç̧ão, progredindo para uma suposta perfeição materializada no homem ou algures no futuro da espécie humana. Isto é um grave erro. Cada espécie é única, o Homo sapiens como o Pan paniscus ou a Drosophila melanogaster. Confunde-se a existência de uma característica única (que não ocorre noutras espécies) com o conceito de "superioridade". Afirmações sobre a "superioridade" do Homem (ou de qualquer outra espécie) não são científicas, e não podem nem ser apoiadas pela possível existência de características exclusivas do homem nem ser refutadas se se demonstrar que as tais características (ou componentes delas) afinal não são únicas. Por isso, o facto de uma dada espécie possuir capacidades que não se encontram noutras espécies não constitui, ou não deveria constituir, qualquer problema. Ninguém considera, por exemplo, que os chapins são "superiores" a outras aves por terem extraordinárias capacidades de memorização espacial, embora o nosso fascínio por essas capacidades possa reflectir a nossa obsessão por especializações cognitivas, ou seja, precisamente o tipo de característica que nos distingue a nós...Assim, investimos mais esforços a estudar os chapins do que, por exemplo, outra característica "extraordinária" (mas não cognitiva) referida por Pinker (1994b), ou seja, a tromba dos elefantes. Entre os mamíferos actuais, apenas as duas espécies de elefantes possuem tromba, havendo portanto um enorme hiato entre elas e qualquer outra espécie em relação ao desenvolvimento deste apêndice. Deveríamos então tentar a todo o custo "lançar pontes" por cima desta descontinuidade, utilizando espécies actuais? Claro que não: a tromba actual, altamente especializada, desenvolveu-se a partir de formas mais primitivas, por processos evolutivos normais. Acontece apenas que as espécies "intermédias" se extinguiram (e não necessariamente por não possuírem uma tromba tão complexa como a actual). $\mathrm{O}$ mesmo aconteceu no caso da linhagem humana. $\mathrm{Na}$ falta dos nossos antepassados directos, recorremos aos chimpanzés, que deixam assim de ser espécies autónomas e transformam-se num mero precursor simplificado da nossa própria espécie. Pior ainda, acabamos por "julgar" outras espécies consoante o grau de semelhança que têm connosco (os chimpanzés passam a ter "maior estatuto" se se demonstrar que possuem capacidades linguísticas), o que é 
simplesmente outro modo de afirmar a nossa "superioridade", ou seja, precisamente a ideia que se julgava combater.

Note-se, ainda no caso do homem, que a posição bípede, tão "única" como a linguagem, não provocou, por comparação com a linguagem, tamanho investimento na "ultrapassagem do hiato". Na verdade, tanto chimpanzés comuns como bonobos (chimpanzés-pigmeus) são capazes de se deslocar, em distâncias curtas, de modo bípede, e podem fazê-lo espontaneamente (ao contrário do que, tanto quanto sabemos, sucede com a utilização de símbolos), embora, claro, sem possuírem as especializações anatómicas que caracterizam os membros da linhagem humana desde Australopithecus. Isto apenas significa que utilizam capacidades gerais, não especializadas, permitidas pela sua anatomia, para exibir certos comportamentos que, no homem, são tão mais especializados que necessitam de adaptações próprias (ou seja, são características derivadas únicas).

Não há portanto nenhuma necessidade de que os chimpanzés possuam aquilo que já tem sido referido como "protolinguagem" (por obscuro que o termo seja) só porque nos referimos a uma característica dos nossos parentes vivos mais próximos (i.e. não extintos), o que vem imbuído da ideia de que se trata de uma versão rudimentar da linguagem. E, com efeito, não é. Além disso, há um equívoco que importa esclarecer: houve pelo menos cinco milhōes de anos de evolução independente das linhagens humana e dos chimpanzés. Na linhagem humana (que, é essencial repeti-lo, não é uma linhagem unidireccional "progredindo" na nossa direcção, mas sim um arbusto de que somos o único ramo sobrevivente), só surgem indicações anatómicas seguras de especializações na laringe com Homo sapiens e, possivelmente, dado que foi descoberto um osso hióide idêntico ao nosso, em Homo neanderthalensis (Arensburg et al., 1989; Lewin, 1993). As especializações cerebrais são ainda mais difíceis de evidenciar. O significado da possível área de Broca em Homo erectus é discutido cepticamente por Walker e Shipman (1996), e assim continua em aberto a questão de quando é que surgiram as fases mais primitivas da linguagem. $\mathrm{O}$ facto de existir, no presente, uma descontinuidade entre o homem e as outras espécies no que respeita às capacidades linguísticas (ou à posição bípede...) não significa que essa descontinuidade tivesse existido ao nível evolutivo, mas apenas que as casualidades da extinção (ou eventualmente a aç̧ão exterminadora directa do Homo sapiens sapiens...) eliminaram as espécies "intermédias". As características que permitem aos chimpanzés utilizar símbolos em laboratório e realizar construçōes gramaticais simples não têm que ser os rudimentos da linguagem ou uma protolinguagem para serem evolutivamente contínuas. Podem sê-lo ou não. Podem depender de estruturas e mecanismos muito diferentes. Podem ser filogeneticamente mais remotas do que se tem presumido, mas ter substratos anatómicos diferentes. Não há dados. É evidentemente plausível que espécies próximas, isto é, da mesma ordem, da mesma superfamilia ou da mesma familia, apresentem continuidade das estruturas para a mesma função, porque terão resolvido os seus "problemas evolutivos" com o mesmo material de base, o que aumenta a probabilidade da continuidade estrutural e funcional de capacidades que de algum modo terão 
alicerçado o aparecimento da linguagem. É a especulação máxima que poderemos fazer à luz do actual conhecimento.

O facto de alguns componentes linguísticos (como símbolos, e aparentemente a importância da sua ordem) poderem ser aprendidos por chimpanzés (ou golfinhos, ou um papagaio) significa apenas que as espécies "bem sucedidas" possuem capacidades simbólicas, presumivelmente derivadas das suas capacidades cognitivas gerais, e que não implicam capacidades especificamente linguísticas. Estas são necessárias para a produção de linguagem mas não são de modo nenhum suficientes. Considerando apenas o léxico, compare-se os 200-500 símbolos (todos não gramaticais, i.e. incluindo apenas substantivos, adjectivos e verbos) adquiridos pelos chimpanzés, utilizando esses processos gerais, com as cerca de 13.000 palavras (incluindo os itens gramaticais que constituem, como vimos, metade das palavras correntemente utilizadas) adquiridas por uma criança de 6-7 anos, utilizando processos linguísticos especializados. A ideia de que as capacidades simbólicas demonstradas por chimpanzés e algumas outras espécies "bastam" (i.e. de que com elas já resolvemos a parte crucial do problema da evolução da linguagem) repousa numa profunda ignorância sobre a verdadeira complexidade da linguagem humana.

O argumento, por vezes invocado, que uma das motivações que levou os investigadores a ensinarem códigos "linguísticos" de comunicação a chimpanzés foi o de "abrir uma janela" sobre o seu mundo cognitivo tem fraca consistência. As observaçōes de Jane Goodall (1986) e Toshisada Nishida (1989) na natureza, ou as de Frans de Waal (1982) em cativeiro "abriram" mais janelas do que qualquer treino linguístico. Para saber do que é que eles gostam, o que é que planeiam, etc., a observação do seu comportamento, das escolhas que fazem, dos seus alimentos, brincadeiras, "alianças", companheiros favoritos, etc., é muito mais eficiente. Não foi a aquisiçăo de alguns símbolos que melhorou a nossa compreensão dos chimpanzés: pelo contrário, foi necessário uma grande familiaridade prévia sobre as suas disposiçōes para que o treino "linguístico" fosse bem sucedido. É talvez apenas ao mundo cognitivo e motivacional do chimpanzé de laboratório, que vive em condiçôes muito particulares, que poderemos aceder de modo muito ténue, utilizando o código com o qual está treinado para responder a questōes várias noutro tipo de testes, como fizeram Premack \& Premack (1983).

A noção de que a linguagem influencia a formação de conceitos e funciona como organizador do pensamento (deduzindo-se portanto que, ao adquirirem "linguagem", os chimpanzés conseguem formar mais conceitos e pensar de modo mais complexo) é igualmente discutível. É uma posição frequentemente defendida por antropólogos, em particular aqueles que pensam que o homem é totalmente determinado pela sua cultura, sem disposiçōes inatas. No seu extremo, leva ao conceito da relatividade linguística, segundo o qual a língua que se fala afecta profundamente o modo como se representa o mundo. Esta ideia foi defendida em relação, por exemplo, à designação das cores (certas línguas têm menos, ou mais, palavras para designar as cores, do que outras e, presumivelmente, os seus praticantes distinguiriam as cores de modo diferente), ou a conceitos temporais 
(por exemplo, Whorf, in Brown, 1991, afirmou que os Hopi não teriam os mesmos conceitos de tempo do que outras culturas visto que a sua língua não os exprime). Estas noçōes são aquilo a que Pinker (1994b) chama "factóides", i.e. ideias sem fundamento, mas repetidas tantas vezes que se tornam dogma. Na realidade foi demonstrado que a percepção das cores e o modo como o espectro contínuo é dividido é muito semelhante em todas as culturas testadas, independentemente do número de palavras utilizadas para designar as cores. Do mesmo modo, a noção de tempo dos Hopi é semelhante à de qualquer outra cultura (ver Brown, 1991). Aliás, como aponta Pinker (1994b), um pouco de reflexão indica imediatamente que é o pensamento que determina o conteúdo da linguagem e não o inverso: quantas vezes sentimos que não exprimimos correctamente o que queríamos dizer? Ora tal sensação seria impossível se a linguagem determinasse o que pensamos. E se fosse assim, como é que se poderia mentir, ou inventar novas palavras? Note-se, incidentalmente, que muitas vezes desconfiamos do que os outros dizem, considerando que as acçỗes valem mais do que as palavras, outra indicação de que há um descolamento entre a linguagem e o pensamento subjacente. É importante não confundir o facto de que a linguagem pode facilitar a nossa compreensão do pensamento dos outros com o facto de ela permitir que os outros pensem! É em parte esta ideia inflacionada sobre a importância da linguagem que anima as tentativas de a ensinar a animais, como se só assim eles pudessem adquirir "estatuto" e complexidade cognitiva.

No que diz respeito a questões ontogenéticas, segundo Savage-Rumbaugh (1986), a comparação dos processos de aquisição de linguagem em chimpanzés e em crianças pode ser esclarecedora, e inclusivamente permitiu iniciar novas abordagens terapêticas a crianças com deficiências mentais com impacto na linguagem. Mais uma vez, esta abordagem baseia-se numa confusão: para que a comparação indique vias evolutivas e para que possa "lançar uma ponte", seria necessário que os processos nos chimpanzés e nas crianças fossem homólogos e não apenas superficialmente semelhantes. Ora é precisamente isso que é necessário demonstrar. $\mathrm{O}$ facto de chimpanzés e crianças normais (até aos dois anos de idade) demonstrarem níveis de compreensão e produção semelhantes não significa que estejam a utilizar processos mentais idênticos: pode ser o caso que os chimpanzés utilizam processos cognitivos gerais, que mantêm toda a vida (incluindo capacidades simbólicas), e que as crianças utilizam processos linguísticos incipientes, os quais, a partir dos dois anos, "explodem". No entanto, mesmo admitindo que nada obriga a que os chimpanzés possam utilizar protolinguagem, ou mesmo componentes isolados do conjunto que constitui a linguagem humana, o único modo de verificar se de facto săo capazes de os adquirir é através de experiências. As experiências com chimpanzés consistiram em ensinar-lhes uma linguagem gestual (em princípio, o american sign language ou ASL) ou com símbolos visuais, devido à sua incapacidade em articular sons como os humanos.

Actualmente, e como vimos acima, admite-se que todas as experiências de aprendizagem linguística em Pongídeos tinham várias falhas metodológicas que 
invalidam qualquer conclusão sobre as capacidades linguísticas dos chimpanzés utilizados. A falha mais óbvia foi o efeito Clever Hans, i.e. a possibilidade de fornecer inconscientemente ao chimpanzé indicaçōes subtis sobre o que ele deve fazer. Particularmente importante nos casos em que foi utilizado o ASL (visto que o experimentador, por força das circunstâncias, estava presente e conhecia a "resposta" correcta), também ocorreu, por exemplo, com Sarah, visto que o desempenho desta se deteriorou espectacularmente no caso em que o experimentador humano era totalmente ignorante no uso dos símbolos. Outra falha importante, sublinhada por Sue Savage-Rumbaugh (1986; Lewin, 1991), foi que se testou demasiado a produção de símbolos, sem assegurar a verdadeira compreensão dos mesmos.

As experiências em que o bonobo Kanzi demonstra a sua compreensão de frases inglesas controlam o efeito Clever Hans, na medida em que Kanzi usa auscultadores e a pessoa que está com ele não ouve a frase que ele ouve e não o pode influenciar. Mas o estudo de Kanzi não difere dos outros no que respeita a outro problema metodológico, o de ver padrõ̃es onde não existem e de sobre-interpretar o que é observado. Por exemplo:

- Kanzi usa displaced reference visto que usa os lexigramas para indicar para onde quer ir ou o que quer fazer. Como diz Wallman (1992, p. 76), um cão que traz a trela ao dono quando quer ir passear faz o mesmo, mas ninguém the atribui capacidades linguísticas.

- Ao admitir que, ao contrário das crianças de menos de dois anos (que comentam, pedem significados, etc.), as expressões de Kanzi são, em $96 \%$ dos casos, pedidos, Greenfield \& Savage-Rumbaugh (1990, p. 567) explicam essa diferença notando que o chimpanzé depende dos humanos para obter o que quer. Como se uma criança de dois anos não dependesse igualmente! Pelo contrário, a diferença entre uma criança e Kanzi no modo como empregam os símbolos adquiridos indicaria que as suas semelhanças são relativamente superficiais e que as crianças, desde o início, utilizam processos diferentes.

- Savage-Rumbaugh (in Wallman, 1992, p. 95) refere combinações multi-simbólicas de Kanzi, quando, na realidade, são, quando muito, combinações de 2 símbolos + 1 gesto (que faz parte do reportório natural dos bonobos) ou 1 símbolo +2 gestos.

- Savage-Rumbaugh (in Wallman, 1992, pp. 102-104; ver também Lewin, 1991; Savage-Rumbaugh \& Rumbaugh, 1993) fala das capacidades sintácticas de Kanzi, i.e. do facto de ele ter que "analisar a estrutura da frase" para interpretar correctamente ordens do tipo: give the trash to Jeaninne.

É óbvio (para quem não quer sobre-interpretar) que Kanzi não necessita de "analisar a estrutura da frase" para executar a ordem. Basta conhecer algumas palavras e manifestar os comportamentos habituais. Eliminemos os elementos gramaticais e: give, trash, Jeaninne ou Jeannine, trash, give só tem uma interpretação possível. 
Para ter a certeza de que Kanzi presta atenção à ordem das palavras, seria necessário utilizar frases mais ambíguas, em que a acção a executar varia com a ordem. Segundo Savage-Rumbaugh \& Rumbaugh (1993), Kanzi interpreta de facto correctamente frases em que a ordem das palavras é essencial, como: make the snake bite the doggie e make the doggie bite the snake: aqui, ambas as acções (executadas com bonecos) são igualmente plausíveis, e a "análise da estrutura da frase" (i.e., da ordem das palavras) é muito mais convincente. Note-se mesmo assim que vários dos outros exemplos referidos por Savage-Rumbaugh e Rumbaugh (1993) pecam por sobre-interpretação: por exemplo, no caso go to the bedroom and get the potato e take the potato to the bedroom, a ordem é irrelevante, sendo apenas necessário saber o significado dos símbolos bedroom, potato, go, get e take (imaginemos: go, bedroom, get, potato, e take, potato, bedroom: só há uma interpretação viável).

Assumindo, no entanto, que Kanzi presta atenção à ordem das palavras, tal não significaria necessariamente que utiliza capacidades sintácticas: com efeito, em inglês existe um isomorfismo entre a sequência das palavras e a sequência das acções. É importante não confundir toda a complexidade da sintaxe com a mera ordem das palavras, talvez a parte mais fácil de analisar. Com efeito, noutras línguas, os casos (e não a ordem das palavras) são as principais indicações sobre a função dos vários elementos da frase. Por exemplo em latim o caso é dado pela terminação das palavras, como em puer puellam vidit (o rapaz/ a rapariga/ viu = o rapaz viu a rapariga), e em japonês o caso é dado por partículas específicas, como $g a$ que indica o sujeito, o que indica o objecto e $n i$ que indica o recipiente da acção, como em komodo ga/ inu ni/mizu o/ yaru (a criança/ ao cão/ água/ dá = a criança dá água ao cão: Crystal, 1987 p. 95). Essas línguas não põem qualquer problema de aprendizagem para as crianças que com elas crescem, mas será que, face a esta ausência de isomorfismo entre a sequência dos símbolos e a sequência das acções, um bonobo (ou qualquer outra espécie) conseguiria demonstrar capacidades sintácticas?

- Finalmente, Savage-Rumbaugh (1993) insiste no facto de Kanzi ter aprendido como o faz uma criança. Mas, tirando o facto de Kanzi não ter sido submetido a condicionamento operante, foi exposto a frases muito mais simples, muito mais repetidas, muito mais destacadas, do que uma criança o seria em condições normais (lembremos que ele assistiu ao treino intensivo da sua mãe adoptiva Matata durante dois anos). Depois de 10 anos disso, a única coisa que Kanzi demonstravelmente possui é a capacidade em reconhecer e utilizar cerca de 200 símbolos arbitrários, e algum vocabulário em inglês. Ao contrário do que ocorre em crianças perto dos dois anos, nas quais surgem a súbita compreensão que "tudo tem um nome", e o desejo de saber os nomes de todos os objectos com os quais contactam, quer necessitem deles ou não, Kanzi (ou qualquer outro chimpanzé estudado) nunca demonstrou compreender que tudo pode ter um nome, nem uma especial vontade em aprender nomes "inúteis", i.e. nomes de objectos que estão presentes mas que não são utilizados. A sua taxa de aprendizagem de novos símbolos não se alterou, enquanto que 
após os dois anos uma criança aprende em média duas novas palavras por hora e consegue lembrar-se de uma palavra nova, mesmo irrelevante para o seu quotidiano, ao fim de cinco semanas, sem a ter utilizado entretanto.... Isto bastaria para indicar que os processos utilizados por Kanzi, para memorizar símbolos, e os processos utilizados por crianças são diferentes. Ora, a aquisiçăo de um vocabulário (o léxico) e a compreensão de significados (semântica) não esgotam nem de longe as capacidades linguísticas que o homem possui (sendo a outra, como vimos, a sintaxe, que inclui muitíssimo mais do que a simples ordem das palavras).

\section{Conclusōes finais}

Os estudos com Pongídeos baseiam-se na necessidade de uma estimulação adequada como premissa fundamental, como situação sine qua non, mas não como condição suficiente, para ter produções linguísticas, sendo que as últimas não ultrapassam competências simbólicas e uso de regras tão simples que a distância dessas elaborações à linguagem é abissal. Esvazia-se assim o conteúdo da palavra "linguística" e retira-se o grande impacto dos resultados dos projectos de estudo da linguagem em Pongídeos, que apenas evidenciam capacidades cognitivas que utilizam nas circunstâncias artificiais dos testes linguísticos inventados pelos investigadores. Ao contrário do que sugerem Piattelli-Palmarini (1989) e Savage-Rumbaugh e Rumbaugh (1993), é a "linguagem" adquirida pelos chimpanzés que é uma exaptação, consequência fortuita de capacidades cognitivas mais gerais, e não a linguagem humana.

A que levou tanto esforço com o ensino da "linguagem" a chimpanzés?

Em primeiro lugar, conhecemos melhor as capacidades cognitivas dos chimpanzés? Se a nossa apreciação a seu respeito aumentou apenas porque conseguem evidenciar, de modo incipiente, algumas das nossas capacidades, estamos de facto a ser mais arrogantemente antropocêntricos do que aqueles cuja apreciação dos chimpanzés não depende de eles terem ou não terem semelhanças connosco. Ao querermos, a todo o custo, eliminar o "hiato" entre eles e nós, estamos no fundo a assumir que à existência de um hiato é significativa de qualquer coisa de profundo (mais profundo do que o hiato entre a tromba dos elefantes e o focinho dos daimōes ou entre a memória dos chapins e a dos pardais), quando não significa nada de especial a não ser para aqueles que, no fundo, acreditam na "superioridade" do homem. E de qualquer modo, a exploração das capacidades simbólicas dos chimpanzés em laboratório pouco contribui para elucidar as suas aptidōes na natureza, embora possa chamar a tenção para questōes ainda antes não notadas. Em condições controladas, estas podem ser exploradas de modo muito mais produtivo do que o ensino da "linguagem" (ver Byrne \& Whiten, 1988; Byrne, 1994; Premack \& Premack, 
1994), embora mesmo este tipo de experiências possa ter problemas de sobre-interpretação (Heyes, 1993). A aquisição de um número limitado de símbolos em laboratório (por comparação com o léxico de qualquer língua humana) bem como a restrita utilização de símbolos gestuais na natureza, tanto quanto os dados do terreno permitem afirmar, não será certamente sintoma de algum tipo de inferioridade na riqueza da comunicação ou das capacidades cognitivas. O que os chimpanzés parecem, na verdade, possuir é uma inteligência adaptada sobretudo à vida social, na qual são altamente especializados e a que Byrne \& Whiten (1988) chamam de inteligência maquiavélica, com a conivência de muitos outros especialistas nestes primatas. Cheney e Seyfarth (1990) descrevem as competências dos macacos verdes (C. aethiops) como um misto de inteligência elevada no que se refere às relações sociais e de uma inteligência relativamente fraca no que se relaciona com os objectos irrelevantes para a sua vida (ao contrário do que sucede com a curiosidade humana, que é muito generalizada). Estes investigadores enfatizam a rapidez com que estes primatas aprendem novas configurações sociais e contrastam-na com a mediocridade da sua competência no que se refere à aprendizagem de características de membros de outras espécies.

Em segundo lugar, percebemos melhor como é que a linguagem humana evoluiu, e quais foram as suas fases mais primitivas? Não, visto que, qualquer que seja a nossa avaliação sobre as capacidades linguísticas reais de Kanzi e de outros chimpanzés, fica por explicar muito mais do que já foi "explicado". Mesmo em pidgin é possível comunicar mais informação do que aquela que é compreendida e produzida por Kanzi. Voltando ao argumento utilizado por Pinker (1994b), dizer que o pouco que se evidenciou nos bonobos adianta significativamente a nossa compreensão da evolução da linguagem, equivale a afirmar que, dado que as espécies actuais mais próximas dos elefantes, os daimões, têm um focinho, já explicámos o essencial da evolução da tromba dos elefantes. Na realidade, falta-nos precisamente explicar o mais interessante...Com efeito, quando é que surgiram as outras capacidades linguísticas humanas não observáveis nos chimpanzés "treinados", como a utilização de preposições, tempos verbais, casos, capacidade em produzir e compreender frases complexas com várias cláusulas, etc. ? Como é que eram as fases primitivas da linguagem? Continuamos sem as respostas, e o trabalho de Savage-Rumbaugh e os seus colaboradores pouco adiantou nesses aspectos cruciais. Pode ser que, no estado actual dos nossos conhecimentos, incluindo o registo fóssil, a questão da origem e evolução da linguagem só possa ser elucidada a partir de melhor compreensão da própria linguagem, em toda a sua verdadeira complexidade, o que pode ser cada vez mais difícil dado que muitas línguas estão a desaparecer. 


\section{Referências}

Arensburg, B., Tillier, A. M., Vandermeersch, B., Duday, H., Schepartz, L. A., \& Rak, Y. (1989). A middle Palaeolithic hyoid bone. Nature, 338, 758-760.

Brown, D. E. (1991). Human universals. Filadélfia: Temple University Press.

Burlig, R. (1993). Primate calls, human language, and non-verbal communication. Current Anthropology, 34 (1), 25-53.

Byrne, R. W. (1994). The evolution of intelligence. In P. J. B. Slater \& T. R. Halliday (Eds.), Behaviour and evolution (pp. 223-265). Cambridge: Cambridge University Press.

Byrne, R. W. \& A. Whiten, (1988) (Eds). Machiavellian Intelligence. Oxford: Clarendon Press.

Calvin, W. H. (1993). The unitary hypothesis: A common neural circuitry for novel manipulations, language, plan-ahead, and throwing? In S. T. Parker \& K. R. Gibson (Eds.), Language and Intelligence in Monkeys and Apes (pp. 230- 249). Cambridge: Cambridge University Press.

Cheney, D. L. \& Seyfarth, R. M. (1990). How Monkeys See the World. Chicago e Londres: University of Chicago Press.

Crystal, D. (1987). The Cambridge encyclopedia of language. Cambridge: Cambridge University Press.

Damásio A. R. \& Damásio, H. (1992). Brain and language. Scientific American, 267, (3), 62-71.

Damásio, H., Grabowski, T. J., Tranel, D., Hichwa, R. D. \& Damásio, A. R. (1996). A neural basis for lexical retrieval. Nature, 380, 499-505.

Davidson, I. \& Noble, W. (1993). Tools and language in human evolution. In S. T. Parker \& K. R. Gibson (Eds.), Language and Intelligence in monkeys and apes (pp. 363- 388). Cambridge: Cambridge University Press.

Dawkins, M. S. (1993). Through our eyes only?: The Search For Animal Consciousness. Oxford, Nova Iorque, Heidelberg: W. H. Freeman / Spektrum.

Deacon, T. (1992). The human brain. In The Cambridge Encyclopedia of Human Evolution (pp. 115- 123). Cambridge: Cambridge University Press.

Fouts, R. S., \& Fouts, D. H. (1989). Loulis in conversation with the cross-fostered chimpanzees. In R. A. Gardner, B. T. Gardner \& T. E. Van Cantford (Eds.), Teaching sign language to chimpanzees (pp. 293-307). Nova Iorque: State University of New York Press.

Gardner, R. A., \& Gardner, B. T. (1969). Teaching sign language to a chimpanzee. Science, 165, 664-672.

Gibson, K. R. (1993). Overlapping neural control of language, gesture and tool-use. In S. T. Parker, \& K. R. Gibson (Eds.), Language and intelligence in monkeys and apes (pp. 187- 192). Cambridge: Cambridge University Press.

Gibson, K. R. \& Ingold, T. (1993). Tools, language and cognition in human evolution. Cambridge: Cambridge University Press.

Glaserfeld, E. V. (1977). The Yerkish language and its automatic parser. In D. Rumbaugh (Ed.), Language learning by a chimpanzee: The Lana project (pp. 91-130). Nova Iorque/ São Francisco / Londres: Academic Press. 
Goodall, J. (1986). The Chimpanzees of Gombe. Cambridge, Massachusetts: Harvard University Press.

Gopnik, M. \& Crago, M. B. (1991). Family aggregation of a developmental language disorder. Cognition, 39, 1-50.

Gordon, B. (1990). Human language. In R. P. Kesner \& D. S. Olton (Eds.), Neurobiology of comparative cognition (pp. 21-49). Nova Jérsia: Lawrence Erlbaum Associates.

Gould, S. J., \& Vrba, E. S. (1982). Exaptation: A missing term in the science of form. Paleobiology, 8, 4-15.

Greenfield, P. M., \& E. S. Savage-Rumbaugh (1990). Grammatical combination in Pan paniscus: Processes of learning and invention in the evolution and development of language. In S. T. Parker \& K. R. Gibson (Eds.), Language and intelligence in monkeys and apes (pp. 540-578). Cambridge: Cambridge University Press.

Heyes, C. M. (1993). Anecdotes, training, trapping and triangulating: Do animals attribute mental states? Animal Behaviour, 46, 177-188.

Hickok, G., Bellugi, U., \& Klima, E. S. (1996). The neurobiology of sign language and its implications for the neural basis of language. Nature, 381, 699-702.

Hockett, C. F. (1960). The origin of speech. Scientific American, 293, 88.

Jablonsky, N., \& Aiello, L. C. (1998). The origin and diversification of language. University of Califórnia: California Press.

Lewin, R. (1991). Look who's talking now. New Scientist, 130 (1766), 49-52.

Lewin, R. (1993). The origin of modern humans. Nova Iorque: Scientific American Library.

Linden, E. (1974). Apes, men and language. Nova Iorque: Saturday Review Press.

Piattelli-Palmarini, M. (1989). Evolution, selection, and cognition: from "learning" to parameter setting in biology and the study of language. Cognition, 31, 1-44.

Pinker, S. (1994a). An instinct for language. New Scientist, 142 (1931), 28-31.

Pinker, S. (1994b). The language instinct. Londres: The Penguin Press.

Pinker, S. (1995). Facts about human language relevant to its evolution. In J. P. Changeux \& J. Chavaillon (Eds.), Origins of the human brain (pp. 258-283). Oxford: Oxford University Press.

Premack, D. (1971). On the assessment of language competence in the chimpanzee. In A. M. Shrier \& Stollnitz (Eds.), Behavior of nonhuman primates (pp. 185-228). Nova Iorque: Academic Press.

Premack, D. \& Premack, A. J. (1983). The mind of an ape. Nova Iorque: W. W. Norton \& Company.

Premack, D., \& Premack, A. J. (1994). Levels of causal understanding in chimpanzees and children. Cognition, 50, 347-362.

Ristau, C. A. \& Robbins, D. (1982). Language in the great apes: A critical review. Advances in the Study of Behavior, 12,141-255.

Savage-Rumbaugh, E. S. (1986). Ape language: From conditioned response to symbol. Oxford: Oxford University Press.

Savage-Rumbaugh, E. S. (1993). Language learnability in man, ape and dolphin. In Roitblat, L. M. Herman \& P. E. Nachtigall (Eds.), Language and communication: comparative perspectives (pp. 457-584). Nova Jérsia: Lawrence Erlbaum Associates. 
Savage, E. S. \& Rumbaugh, D. M. (1977). Communication, language and lana: A perspective. In D. Rumbaugh (Ed.), Language learning by a chimpanzee. The Lana project (pp. 287-312). Nova Iorque/ São Francisco / Londres: Academic Press.

Savage-Rumbaugh, E. S., \& Rumbaugh, D. M. (1993). The emergence of language. In K. R. Gibson \& T. Ingold (Eds.), Tools, language and cognition in human evolution (pp. 86-108). Cambridge: Cambridge University Press.

Sherry, D. F., \& Duff, S. J. (1996). Behavioural and neural bases of orientation in food-storing birds. Journal of Experimental Biology, 199, 165-172.

Shettleworth, S. (1983). Memory in food-hoarding birds. Scientific American, 248, 86-94.

Terrace, H. S., Petitto, L. A., Sanders, R. J. \& Bever, T. G. (1979). Can an ape create a sentence? Science, 206, 891-902.

Thorpe, J. (1972). Principles of textual criticism. San Marino, CA: Huntington Library.

Vieira, A. B. (1994). Ferramentas líticas e origem da linguagem. Ethnologia, 1-2, 109-126.

Vieira, A. B. (1995). Ensaios Sobre a evolução do homem e da linguagem. Lisboa: Fim de Século.

de Waal, F. B. M. (1982). Chimpanzee politics: Power and sex among apes. Londres: Jonathan Cape.

Walker, A. \& Shipman, P. (1996). The wisdom of bones. Londres: Weidenfeld \& Nicholson. Wallman, J. (1992). Aping Language. Cambridge: Cambridge University Press.

Language in humans and chimpanzees: A semantics' problem (abstract) In this paper we review some of the major studies investigating the so called "chimpanzee language" or the "linguistic abilities of apes" and try to sort out what exactly have they demonstrated, what are the assumptions underlying such studies, their motivations and their methodological problems. A considerable number of concepts have also been reviewed, since a broad use of the term "language" generated a great deal of confusion about the real meaning and extent of the finding of cognitive abilities in apes that are important requirements for the emergence of language, but by no means reach the level of complexity that defines the human language. 